\title{
Prevalence of porcine parvovirus in pigs with postweaning multisystemic wasting syndrome in Jeju Island
}

\author{
Kyeong-Nam Ko ${ }^{1}$, Ji-Youl Jung ${ }^{1}$, Sang-Chul Kang ${ }^{1}$, Ki-Seung Kim ${ }^{1}$, Jae-Hoon Kim ${ }^{1}$, Dae-Yong Kim ${ }^{2}$, \\ Eui-Kyung Hwang, Jae-Hoon Kim ${ }^{1, *}$ \\ ${ }^{I}$ College of Veterinary Medicine and Veterinary Medical Research Institute, Jeju National University, \\ Jeju 690-756, Korea \\ ${ }^{2}$ College of Veterinary Medicine, Seoul National University, Seoul 151-742, Korea \\ ${ }^{3}$ College of Life Science and Natural Resources, Sangji University, Wonju 220-702, Korea \\ (Received: May 27, 2010; Revised: January 06, 2011; Accepted: January 06, 2011)
}

\begin{abstract}
Postweaning multisystemic wasting syndrome (PMWS), which was first identified in western Canada in 1991 and more recently in the United States, Europe and Asia, is an emerging disease in pigs. Porcine circovirus type 2 (PCV-2) is the primary infectious viral agent causing PMWS, but the full expression of the disease may require the presence of other agents. It is reported that there is apparent synergism between PCV-2 and porcine parvovirus (PPV) in increasing the severity of the clinical signs and lesions of PMWS. From January 2006 to May 2008, a total of the 154 lymph node samples were collected from $4 \sim 12$ weeks old pigs which had been submitted to the College of Veterinary Medicine, Jeju National University, Korea. These pigs were diagnosed as PMWS on the basis of clinical and pathological examination from 48 commercial herds in Jeju Island. Based on the immunohistochemistry, porcine parvovirus was detected in 69 cases $(44.8 \%)$ from 154 weaned or grower pigs. PPV antigens were detected in the cytoplasm of histiocytic cells multifocally infiltrated in the cortex and paracortex of lymph nodes. The results of this study clarify that PPV is prevalent in pigs with PMWS on Jeju Island. Therefore PPV is one of the most important co-agents in the development of naturally acquired PMWS. This study may be helpful to the control of this disease and to epidemiological aspects.
\end{abstract}

Keywords : co-infection, immunohistochemistry, Jeju Island, PMWS, porcine parvovirus

\section{Introduction}

Postweaning multisystemic wasting syndrome (PMWS) is an emerging disease in pigs in Canada, the United States, Europe and Asia and was first identified in western Canada in 1991. This chronic, insidious and sometimes protracted disease occurs most commonly in 5 to 12 weeks old pigs [1, 6]. Morbidity and mortality associated with PMWS vary depending on the stage of the outbreak and management within affected units with rates varying $4 \sim 30$ and 50 90\%, respectively [1, 18].

Common presenting clinical signs include wasting or unthriftiness, dyspnea, visibly enlarged lymph nodes, and less frequently pallor, diarrhea and jaundice $[5,6]$. Interstitial pneumonia, lymphadenopathy, hepatitis and nephritis are prominent post-mortem findings. Histopatho- logical lesions include macrophage infiltration, lymphocytic depletion and syncytia formation in lymphoid tissues and granulomatous lesions in a wide range of non-lymphoid tissues $[1,18]$. And variable numbers of intracytoplasmic amphophilic viral inclusion bodies were occasionally seen within infiltrating histiocytes and macrophages [2, 10].

A consistent association between PMWS and infection by porcine circovirus type $2(\mathrm{PCV}-2)$ in pigs with naturally acquired disease has been demonstrated [6]. PCV-2 is the primary infectious viral agent causing PMWS $[1,6]$, but the full expression of the disease may require the presence of other agents such as porcine reproductive respiratory syndrome virus (PRRSV), porcine parvovirus (PPV), Aujeszky's disease virus, Haemophilus parasuis, Pasteurella multocida and Bordetella bronchiseptica $[1,2,4,5,8,9]$.

\footnotetext{
*Corresponding author

Tel: +82-64-754-3387, Fax: +82-64-702-9920

E-mail: kimjhoon@jejunu.ac.kr
} 
Co-infection of PCV-2 and PPV has been demonstrated in a significant proportion of field cases of PMWS in pigs in Korea and Canada [3, 4, 10]. Many studies on experimental reproduction of PMWS by infection of conventional or gnotobiotic pigs with PCV-2 alone or in combination with PPV demonstrated that severe clinical disease and death with typical PMWS lesions. This indicates that there is an apparent synergism between PCV-2 and PPV in the disease development [2, $8,9,11,15]$.

This study was carried out to investigate the prevalence of concurrent infection by PCV-2 and PPV in pigs with PMWS in Jeju Island.

\section{Materials and Methods}

\section{Tissue samples and histopathology}

From January 2006 to May 2008, a total of the 154 lymph node samples were collected from $4 \sim 12$ week old pigs which had been submitted to the Pathology Department of College of Veterinary Medicine, Jeju National University (Korea) from 48 commercial herds in Jeju Island. These pigs were diagnosed as PMWS on the basis of clinical and pathological examination including histological findings and polymerase chain reaction to identify the PCV-2 nucleic acid in samples from the superficial inguinal lymph node and lung. These were 63 cases from 27 herds in 2006, 66 cases from 22 herds in 2007 and 25 cases from 9 herds in 2008, respectively. 10 pig herds submitted dual samples during the designed period of this study. Negative control lymph node tissues were prepared from 1-day-old colostrum-deprived pigs in Jeju.

All lymph node samples were collected from pigs at necropsy. They were fixed with $10 \%$ neutral buffered formalin for histopathologic examination. According to the standard tissue processing method, tissue samples were embedded in paraffin wax, cut into $2 \sim 3 \mu \mathrm{m}$-thick sections and stained with H\&E for light microscopic examination.

\section{Immunohistochemistry (IHC)}

To investigate the presence of PPV antigen in lymph node tissues, immunohistochemical identification was performed with a labeled streptavidin-biotin-peroxidase method. The sections were placed on silane-coated slides, deparaffinized and rehydrated. They were quenched with $3 \%$ hydrogen peroxide $\left(\mathrm{H}_{2} \mathrm{O}_{2}\right)$ in phosphate-

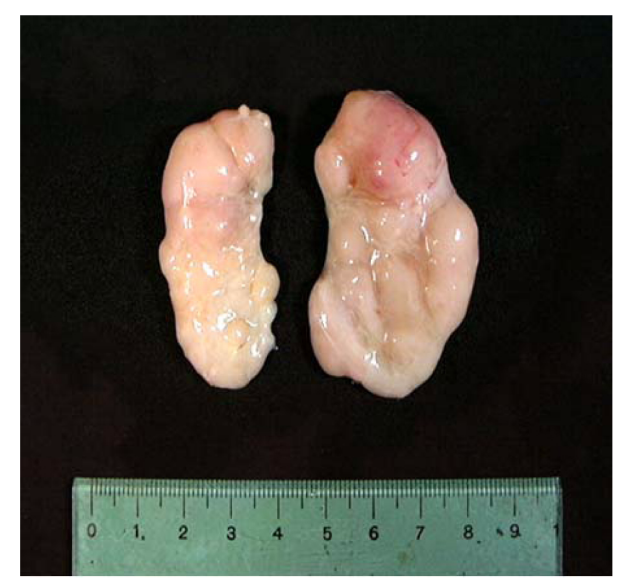

Fig. 1. Lymph node. Inguinal lymph nodes infected with porcine circovirus type 2 and porcine parvovirus were severely enlarged.

buffered saline (PBS) for $10 \mathrm{~min}$ to remove endogenous peroxidase and digested with $0.05 \%$ protease XIV (Sigma, USA) for $10 \mathrm{~min}$ at $37^{\circ} \mathrm{C}$ for antigen retrieval. After rinsing in PBS, they were incubated with primary mouse monoclonal antibody to PPV (VMRD, USA) which was diluted $(1: 300)$ in antibody diluent solution (Dako, USA) at $37^{\circ} \mathrm{C}$ for $1 \mathrm{~h}$. After washing in PBS, a solution of biotinylated antibody (Dako, USA) was applied to the sections for $40 \mathrm{~min}$ at $37^{\circ} \mathrm{C}$. They were then washed in PBS and a streptavidin-horseradish peroxidase (Dako, USA) was applied for $30 \mathrm{~min}$ at $37^{\circ} \mathrm{C}$. The reaction visualized by applying $1 \% 3,3^{\prime}-$ diaminobenzidine tetrahydrochloride, DAB chromogen (Dako, USA), for $2 \sim 4 \mathrm{~min}$. Finally the sections were counterstained with Mayer's hematoxylin.

\section{Results}

\section{Clinical signs and Gross findings}

All pigs showed typical clinical signs of PMWS including wasting, dyspnea, visibly enlarged lymph nodes and sometimes diarrhea. At necropsy, common gross findings were mainly characterized by interstitial pneumonia and markedly enlarged general lymph nodes (Fig. 1), especially involving the inguinal, mesenteric, bronchial lymph nodes.

\section{Histopathological lesions}

Histopathologically, although the severity varied, the lesions of PMWS affected lymph nodes were consistently characterized by multifocal granulomatous inflammation. 

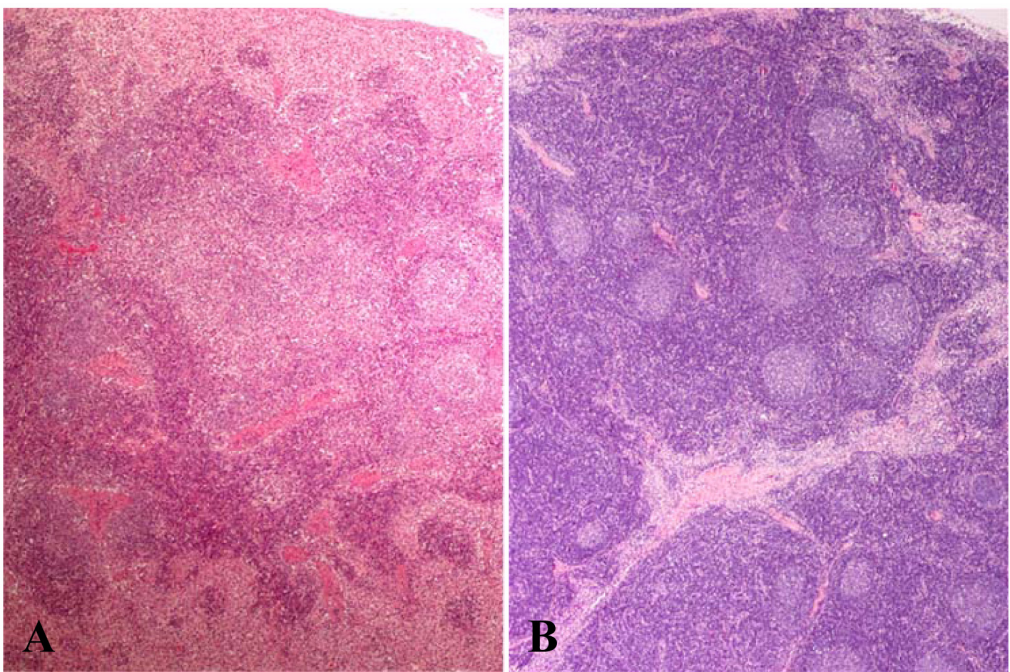

Fig. 2. Lymph node. Lymphocytes depletion in lymphoid follicles and histiocytic cells infiltration in the cortex and paracortex. (A) Normal lymph node. (B) H\&E Stain, $\times 40$.

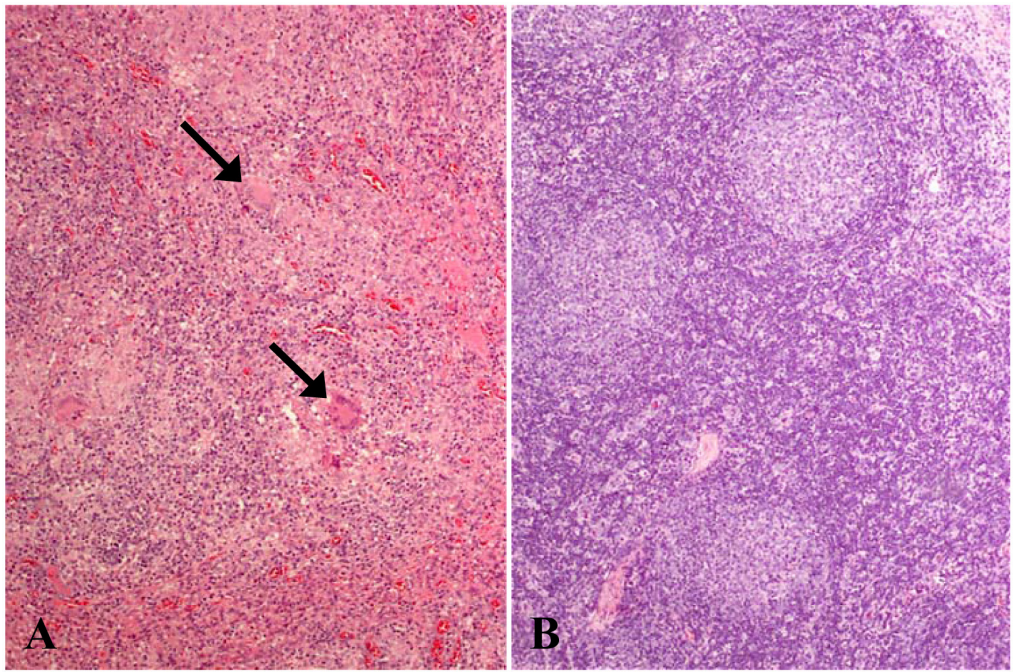

Fig. 3. Lymph node. Note multinucleated giant cells (arrows). (A) Normal lymph node. (B) H\&E Stain, $\times 100$.

Depletion of lymphoid follicles (B cell dependent areas mainly), reduced or absent germinal centers and multifocal to diffuse infiltration of paracortex ( $\mathrm{T}$ cell dependent areas) and cortex with large histiocytic cells (Fig. 2) and some multinucleated giant cells (Fig. 3) were observed in H\&E stain. And grape-like basophilic or amphophilic intracytoplasmic inclusion bodies were occasionally seen in infiltrated histiocytic cells and multinucleated giant cells in those areas (Fig. 4). In advanced stage, generalized depletion of lymphoid cells and prominent fibro-reticular stroma, medulla-like cords, severely appeared in lymph nodes.

\section{IHC}

In IHC, although the extent of positive cells varied, PPV was detected in 69 cases $(44.8 \%)$ from 154 weaned or grower pigs. By years, 20 of 63 cases (31.7\%), 37 of 66 cases $(56.1 \%)$ and 12 of 25 cases (48\%) were positive for PPV in 2006, 2007 and 2008, respectively. PPV antigens were detected sporadically throughout the 


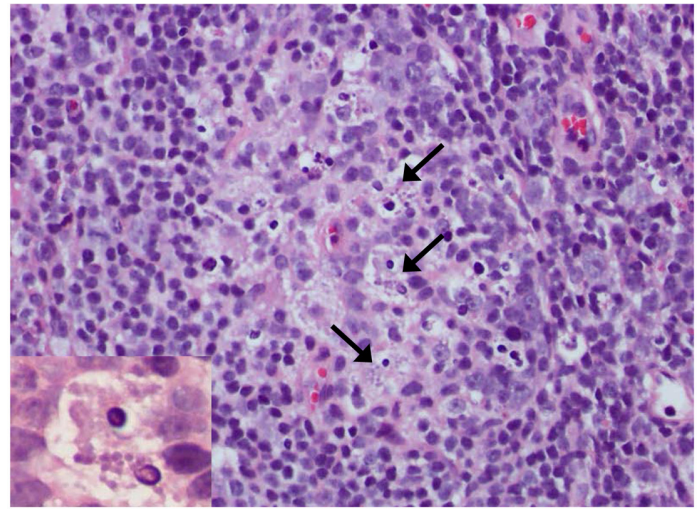

Fig. 4. Lymph node. Grape-like basophilic or amphophilic intracytoplasmic inclusion bodies (insert: $\times 1,000)$ in infiltrated histiocyte (arrows). H\&E Stain, $\times 400$.

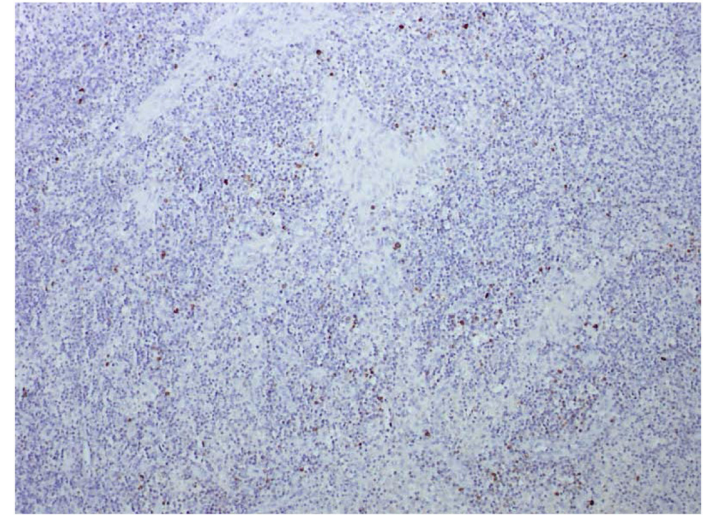

Fig. 5. Lymph node. Positive reactions for porcine parvovirus (PPV) antigens were scattered in lymph node. Streptavidin-biotin peroxidase stain, $\times 100$.

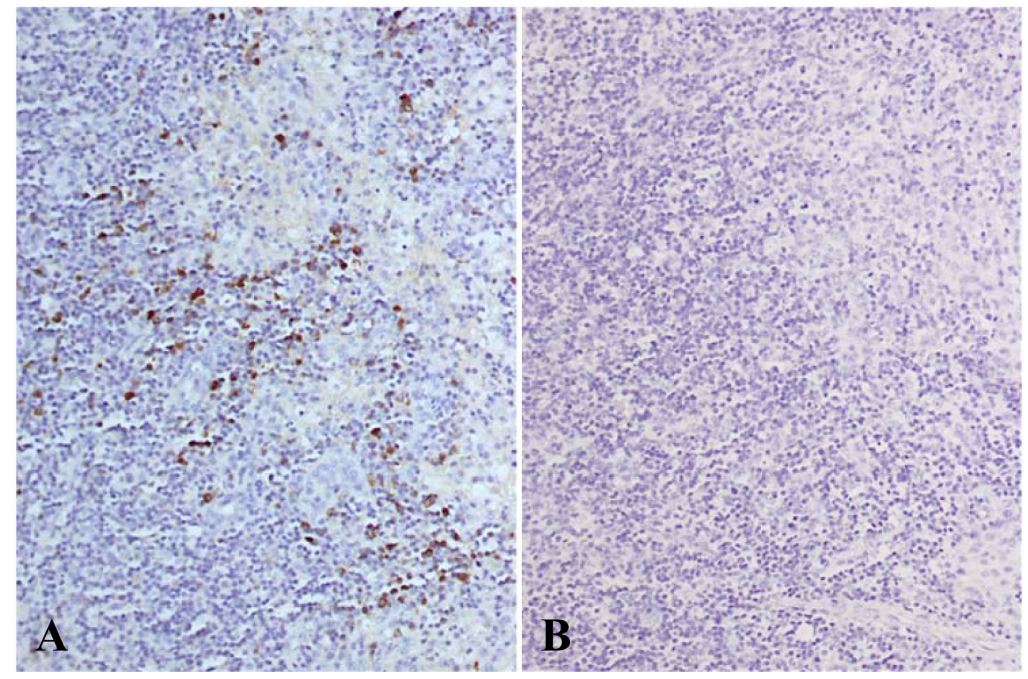

Fig. 6. Lymph node. Positive reactions for PPV antigens in the cytoplasm of infiltrated histiocytic cells of the cortex and paracortex. (A) Negative reaction in normal lymph node. (B) Streptavidin-biotin peroxidase stain, $\times 200$.

lymph node (Fig. 5). However IHC positive signal was focused in cortex and paracortex. PPV antigens were labeled with a dark brown reaction product in the cytoplasm of histiocytic cells multifocally infiltrated in the cortex and paracortex of lymph nodes (Fig. 6).

\section{Discussion}

PMWS of pigs can cause great economic losses because it has been most commonly diagnosed in high health herds [1] and is associated with relatively high fatality risk in comparison with a low morbidity mainly in nursery and early growing pigs $[1,10]$. PCV-2 is thought to be apparently endemic in pig populations throughout the world [5]. PPV also has the apparent endemic nature in the world's swine populations [13]. Although the infection of growing pigs with PPV alone is not generally associated with clinical disease, subclinical or convalescent pigs infected with PPV may remain carriers after seroconversion and may serve as a source of virus transmission to other animals $[2,8,11]$.

Although PPV is not regarded as being a significant cause of mortality in young pigs [4], PPV is one of important co-agents in the development of naturally acquired PMWS, like PRRSV [2, 4, 9, 11, 15] Many studies have demonstrated an apparent synergism between 
PCV-2 and PPV in increasing the severity of the clinical signs and lesions of PMWS [2, 8, 9, 11, 15]. Therefore, the increase of co-infections with PCV-2 and PPV would result in much greater economic losses because the dual infection can induce subclinical PMWS to clinical PMWS and develop the disease more severe.

The precise mechanisms by which PCV-2 and PPV interact synergistically to produce more severe disease in co-infected pigs remain to be determined, but may involve enhancement of PCV-2 replication in macrophages or other target cells [5]. It is thought that stimulation of host DNA to enter the S-phase of the cell cycle by PPV promotes PCV-2 replication [11]. Both PPV and PCV have a predilection for monocyte-macrophage lineage of lymphoid tissue $[2,6,7]$ and may target the same cells in vivo [4]. The replicative cycle of PCV-2 and PPV requires or makes the use of actively replicating cells [12]. And it is likely that factors that affect the replication of potential target cells would affect viral replication and, by extension, viral load and disease. Therefore, PPV that cause the death of target cells and lead to regeneration of damaged tissue may indirectly enhance the replication of PCV-2 [5]. That is to say, new DNA synthesis, mitosis and proliferation of histiocytes and macrophages induced by monocyte proliferation signals of PPV [11] provided the optimal conditions for PCV-2 replication and dissemination in vivo $[8,9]$. In addition, immunosuppression induced by PCV-2 and PPV may be the mechanism that accounts for the synergistic relationship between the PCV-2 and PPV infections and the clinical expression of PMWS [3, 7, 8, 11, 18].

Nevertheless, there are few published data from the study for the prevalence of PPV in pigs with PMWS. In one previous report, approximately $17 \%$ of PCV-2 infected western Canadian pigs with PMWS had evidence of co-infection with PPV [4]. In Korea, Kim et al. [10] reported that PMWS is widely distributed in the Republic of Korea and the prevalence of coinfections by PCV-2 and PPV was $25.6 \%$ (34/133) in 2001. In this study, the overall prevalence of coinfections by PCV-2 and PPV determined by immunohistochemisty was $44.8 \%$ (69/154). Although the different samples and methods applied, PPV infection was more prevalent in pigs with PMWS in Jeju. This finding indicates that, there is possibility of more severe clinical situation of PMWS in Jeju Island comparing with mainland of Korea.

There have been several studies on the effect of PPV vaccination in the development of PMWS. Opriessnig et al. [14] were not able to experimentally prove a positive effect of PPV vaccination in reducing the incidence of clinical PMWS in PCV-2/PPV coinfected pigs, though reduction in morbidity and mortality of grow-finish pigs affected by PMWS and respiratory disease has been repeatedly achieved in the field with the use of PPV vaccines. Another approach to reduce the losses in weaning pigs due to coinfection with PCV2 and PPV could be through hyperimmunization of the breeding herd against PPV [14]. It had reported that vaccination of sows may even be more practical than vaccinating growing pigs, and the potential adverse vaccine dependent-effect on PCV-2 replication in growing pigs could be avoided [14]. Actually, in a study for the effect of PPV vaccination on PMWS and PCV-2 genome load in the offspring of sows, it was showed that the amount of PCV-2 replication, as the genome load was far higher in piglets born to PCV-2-infected nonvaccinated sows than in piglets born to infected vaccinated sows [17]. Transfer of passive immunity from the dam to the litter is a key management factor [16, 17]. Passive immunity protected against the clinical symptoms and the probability of PCV-2 infection; in addition, the numbers of PCV-2 genome copies per gram of tissue were significantly higher for piglets without PCV-2 passive immunity than for those with such immunity [17].

The results of this study clarify that PPV is prevalent in pigs with PMWS on Jeju Island. Because concurrent infection with PPV increased the severity of PMWS lesions, more effective preventive measures for this disease should be performed in Jeju Island. Additional studies are needed to determine the precise mechanism of the interaction between these two viruses in the pathogenesis of PMWS.

\section{Acknowledgments}

This work was supported by a grant (Code \#20070401034009) from BioGreen 21 Program, Rural Development Administration, Republic of Korea.

\section{References}

1. Allan GM, Ellis JA. Porcine circoviruses: a review. J Vet Diagn Invest 2000, 12, 3-14.

2. Allan GM, Kennedy S, McNeilly F, Foster JC, Ellis 
JA, Krakowka SJ, Meehan BM, Adair BM. Experimental reproduction of severe wasting disease by co-infection of pigs with porcine circovirus and porcine parvovirus. J Comp Pathol 1999, 121, 1-11.

3. Choi C, Chae C. Distribution of porcine parvovirus in porcine circovirus 2-infected pigs with postweaning multisystemic wasting syndrome as shown by in-situ hybridization. J Comp Pathol 2000, 123, 302-305.

4. Ellis JA, Bratanich A, Clark EG, Allan G, Meehan B, Haines DM, Harding J, West KH, Krakowka S, Konoby C, Hassard L, Martin K, MeNeilly F. Coinfection by porcine circoviruses and porcine parvovirus in pigs with naturally acquired postweaning multisystemic wasting syndrome. $\mathbf{J}$ Vet Diagn Invest 2000, 12, 21-27.

5. Ellis J, Clark E, Haines D, West K, Krakowka S, Kennedy S, Allan GM. Porcine circovirus-2 and concurrent infections in the field. Vet Microbiol 2004, 98, 159-163.

6. Ellis J, Hassard L, Clark E, Harding J, Allan G, Willson P, Strokappe J, Martin K, McNeilly F, Meehan B, Todd D, Haines D. Isolation of circovirus from lesions of pigs with postweaning multisystemic wasting syndrome. Can Vet J 1998, 39, 44-51.

7. Harding MJ, Molitor TW. Porcine parvovirus: replication in and inhibition of selected cellular functions of swine alveolar macrophages and peripheral blood lymphocytes. Arch Virol 1988, 101, 105-117.

8. Kennedy S, Moffett D, McNeilly F, Meehan B, Ellis J, Krakowka S, Allan GM. Reproduction of lesions of postweaning multisystemic wasting syndrome by infection of conventional pigs with porcine circovirus type 2 alone or in combination with porcine parvovirus. J Comp Pathol 2000, 122, 9-24.

9. Kim J, Choi C, Chae C. Pathogenesis of postweaning multisystemic wasting syndrome reproduced by coinfection with Korean isolates of porcine circovirus 2 and porcine parvovirus. J Comp Pathol 2003, 128, 5259.

10. Kim J, Chung HK, Jung T, Cho WS, Choi C, Chae C. Postweaning multisystemic wasting syndrome of pigs in Korea: prevalence, microscopic lesions and coexisting microorganisms. J Vet Med Sci 2002, 64, 57-62.

11. Krakowka S, Ellis JA, Meehan B, Kennedy S, McNeilly F, Allan G. Viral wasting syndrome of swine:
Experimental reproduction of postweaning multisystemic wasting syndrome in gnotobiotic swine by coinfection with porcine circovirus 2 and porcine parvovirus. Vet Pathol 2000, 37, 254-263.

12. Meehan BM, McNeilly F, Todd D, Kennedy S, Jewhurst VA, Ellis JA, Hassard LE, Clark EG, Haines DM, Allan GM. Characterization of novel circovirus DNAs associated with wasting syndromes in pigs. J Gen Virol 1998, 79, 2171-2179.

13. Mengeling WL. Porcine parvovirus. In: Straw BE, D'Allaire S, Mengeling WL, Taylor DJ (eds.). Diseases of Swine. 8th ed. pp. 187-200, Iowa State University Press, Ames, 1999.

14. Opriessnig T, Fenaux M, Yu S, Evans RB, Cavanaugh D, Gallup JM, Pallares FJ, Thacker EL, Lager KM, Meng X.J, Halbur PG. Effect of porcine parvovirus vaccination on the development of PMWS in segregated early weaned pigs coinfected with type 2 porcine circovirus and porcine parvovirus. Vet Microbiol 2004, 98, 209-220.

15. Ostanello F, Caprioli A, Di Francesco A, Battilani M, Sala G, Sarli G, Mandrioli L, McNeilly F, Allan GM, Prosperi S. Experimental infection of 3-week-old conventional colostrum-fed pigs with porcine circovirus type 2 and porcine parvovirus. Vet Microbiol 2005, 108, 179-186.

16. Rose N, Abhervé-Guéguen A, Le Diguerher G, Eveno E, Jolly JP, Blanchard P, Oger A, Jestin A, Madec F. Effect of the Pietrain breed used as terminal boar on post-weaning multisystemic wasting syndrome (PMWS) in the offspring in four PMWS-affected farms. Livest Prod Sci 2005, 95, 177-186.

17. Rose N, Blanchard $\mathbf{P}$, Cariolet $\mathbf{R}$, Grasland $\mathbf{B}$, Amenna N, Oger A, Durand B, Balasch M, Jestin A, Madec F. Vaccination of porcine circovirus type 2 (PCV2)-infected sows against porcine parvovirus (PPV) and Erysipelas: effect on post-weaning multisystemic wasting syndrome (PMWS) and on PCV2 genome load in the offspring. J Comp Pathol 2007, 136, 133-144.

18. Segalés J, Domingo M, Chianini F, Majó N, Domínguez J, Darwich $\mathbf{L}$, Mateu E. Immunosuppression in postweaning multisystemic wasting syndrome affected pigs. Vet Microbiol 2004, 98, 151158. 